\title{
REMOVAL OF DYES FROM AQUEOUS SOLUTIONS BY ADSORPTION ON MIXTURES OF FLY ASH AND SOIL IN BATCH AND COLUMN TECHNIQUES
}

\author{
T.A. ALBANIS* \\ D.G. HELA \\ T.M. SAKELLARIDES and \\ T.G. DANIS
}

Received: 24/03/00

Accepted: $24 / 11 / 00$

\author{
Department of Chemistry \\ University of Ioannina \\ Ioannina GR-451 10, Greece
}

* to whom all correspondence should be addressed tel.: +30-651-98348; fax.: +30-651-44836 e-mail: talbanis@cc.uoi.gr

\begin{abstract}
Adsorption and removal of commercial dyes were studied in aqueous suspensions of fly ash mixtures with a sandy clay loam soil of low organic matter content. The commercial dyes, acid orange 7 , acid yellow 23, disperse blue 79, basic yellow 28 and direct yellow 28 represent the widely used nitroazo structures. Batch and column experiments were carried out at equilibrium conditions for concentrations of dyes between 5 and $60 \mathrm{mg} \mathrm{l}^{-1}$. The logarithmic form of Freundlich equation gave a high linearity and the $\mathrm{k}$ constants are increasing with the increase of fly ash content in adsorbent mixtures and the affinity between the adsorbent surface and adsorbed solute. The mean removed amounts of dyes by adsorption batch experiments in soil mixture with $20 \%$ fly ash content were up to $53.0 \%$ for acid yellow 7 , $44.9 \%$ for acid yellow 23, $99.2 \%$ for direct yellow $28,96.8 \%$ for basic yellow 28 and $88.5 \%$ for disperse blue 79 . The removal of dyes from column experiments decrease with the increase of the solution concentration form 10 to $50 \mathrm{mg} \mathrm{l}^{-1}$ at $20{ }^{\circ} \mathrm{C}$, showing the process to be highly dependent on the concentration of the solution. The mean removed amounts of dyes by adsorption on columns of soil mixture with $20 \%$ fly ash content and for initial concentration of dye solutions $50 \mathrm{mg} \mathrm{l}^{-1}$ were up to $33.8 \%$ for acid yellow 7, 59.4\% for acid yellow 23, 84.2\% for direct yellow 28, 98.2\% for basic yellow 28 and $60.3 \%$ for disperse blue 79 .
\end{abstract}

KEYWORDS: azo dyes, fly ash, soil, adsorption, removal, batch, column techniques

\section{INTRODUCTION}

Among the different pollutants of aquatic ecosystems, dyes are a large and important group of industrial chemicals for which world production in 1978 was estimated at 640,000 tons (Clarke and Anliker, 1980). Most of this quantity was used in the textile industry and the dyes in use include many different compounds and their environmental behavior is largely unknown (Baughman and Perenich, 1988). Most dyes and pigments are considered either inert or non-toxic, although some are not totally innocuous (Laing, 1991). Interest in the environmental behavior of dyes is prompted primarily by concern over their possible toxicity 
and carcinogenicity, heightened by the fact that many dyes formerly were made of known carcinogens such as benzidine, which may be reformed as a result of metabolism (Clarke and Anliker, 1980; Baughman and Perenich, 1988). Disperse dyes have been shown to have high partition coefficients and solubility, suggesting significant potential for bioconcentration (Anliker et al.,1981). Dye toxicity is not well defined in plant effluents and their long-term effects on animal and human health are not documented, with an exception of a study by Sturm and co-workers (Sturm et al., 1975).

Most dyestuffs are designed to be resistant to environmental conditions like light, effects of $\mathrm{pH}$ and microbial attack (Pagga and Jaeger, 1994). Hence, their presence in wastewater is unwarranted, and it is desirable to remove coloring material from effluents, before their discharge in the environment, not only for aesthetic reasons. This is important to regions where water resources might be scarce or sensitive.

The removal of such compounds at such low levels consists a difficult problem. Among the meth-
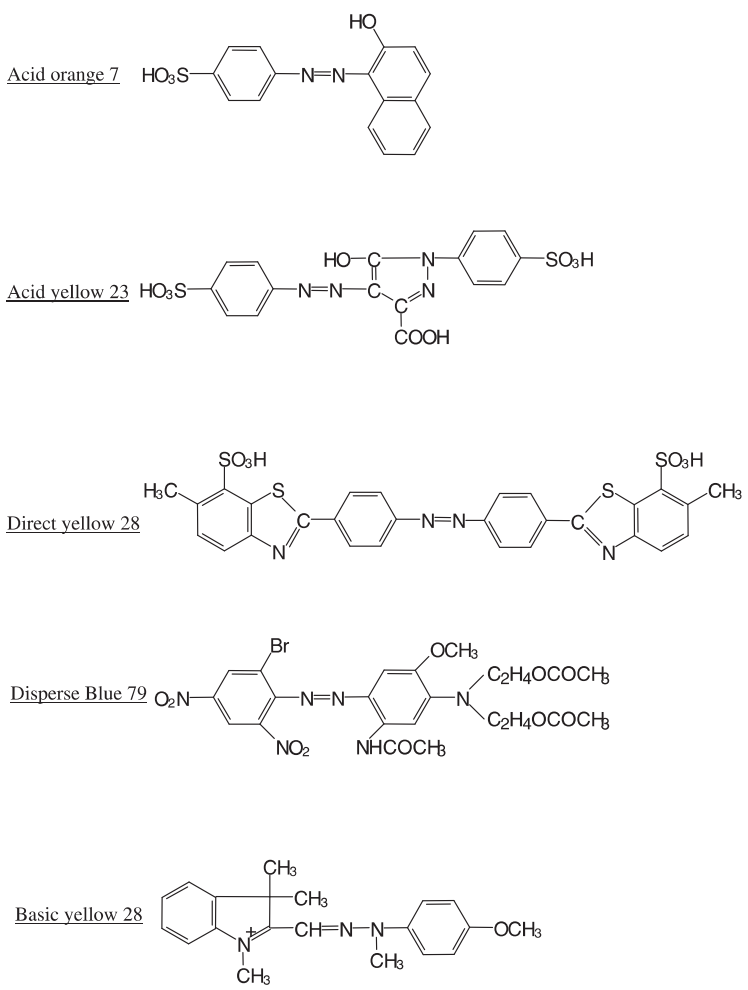

Figure 1. Selected dyes for the adsorption study. ods employed are the adsorption onto sludge of waste water treatment plant, as well as other physicochemical techniques as coagulation, flocculation, ozonation, reverse osmosis and adsorption on activated carbon, manganese oxide, silica gel and clays (Davis and Randal, 1978; Pollock, 1973;. Arvanitoyannis et al., 1987; Arvanitoyannis et al., 1989; Nyholm et al., 1992; Mavros et al., 1994). The biological processes typically accomplish very little towards color removal (Davis and Randal, 1978).

The purpose of this work is the study of the removal of selected azo and anthraquinone dyes from water, by adsorption on mixtures of a typical SCL (sandy clay loam) soil with fly ash and organic matter, in batch or columns. Five particular dyes were chosen for the experiments (Figure 1): Acid Orange 7 (CI 15510); Acid Yellow 23 (CI 19140); Direct Yellow 28 (CI 19555); Basic Yellow 28 (CI 41000); Disperse Blue 79 (CI 11345).

\section{EXPERIMENTAL PROCEDURE}

The soil samples were collected from the region of Preveza (Greece) from a depth between $0-10 \mathrm{~cm}$. The collected soil was SCL with a composition of $29 \%$ clay, $22 \%$ silt, $49 \%$ sand and a content of organic matter $0.67 \%$. Soil $\mathrm{pH}$ was 6.6 (soil: distilled water, 1:1 w/v) and its specific surface area was $5.64 \mathrm{~m}^{2} \mathrm{~g}^{-1}$. The fly ash was from the Thermal Station (raw material lignite) of Public Organization of Electricity at Ptolemaida (Greece) and its chemical composition and physicochemical properties are shown in Table 1. The surface area of fly ash and soil particles was determined by the nitrogen adsorption method (BET). Amounts of fly ash $0-20 \%$ were mixed with soil in order to have sorbents which permit high flow rates of aquatic dye solutions through the columns. The fly ash content of these mixtures and their $\mathrm{pH}$ values are shown in Table 2 .

The dyes shown in Figure 1 were used as commercial formulations. Aqueous solutions of each of the tested dyes (Figure 1) were prepared in final concentrations of 5, 10, 20, 40 and $60 \mathrm{mg} \mathrm{l}^{-1}$. The batch adsorption experiments were carried out in $40 \mathrm{ml}$ polypropylene centrifuge tubes where $1 \mathrm{~g}$ of soil and fly ash mixtures and $25 \mathrm{ml}$ of the above dye solutions were added. All experiments were run under an atmosphere of $\mathrm{N}_{2}$ in order to exclude oxygen which promotes the aer- 
Table 1. Chemical composition and characteristics of fly ash

\begin{tabular}{lcll}
\hline Component & $(\%)$ & Component & $(\%)$ \\
\hline $\mathrm{SiO}_{2}$ & 38.90 & $\mathrm{MgO}$ & 2.30 \\
$\mathrm{Fe}_{2} \mathrm{O}_{3}$ & 5.18 & $\mathrm{SO}_{3}$ & 5.75 \\
$\mathrm{Al}_{2} \mathrm{O}_{3}$ & 19.50 & $\mathrm{Na}_{2} \mathrm{O}$ & 0.78 \\
$\mathrm{TiO}_{2}$ & 0.32 & $\mathrm{~K}_{2} \mathrm{O}$ & 1.13 \\
$\mathrm{CaO}$ & 26.60 & & \\
Surface area & $7.85 \mathrm{~m}^{2} \mathrm{~g}^{-1}$ & & \\
\hline
\end{tabular}

Table 2. $\mathrm{pH}^{*}$ values of SCL soil and fly ash mixtures

\begin{tabular}{lccc}
\hline Fly ash $(\%)$ & $\mathrm{pH}$ & Fly ash $(\%)$ & $\mathrm{pH}$ \\
\hline 0 & 7.25 & 10 & 9.56 \\
2.5 & 7.78 & 20 & 10.23 \\
5 & 8.64 & 100 & 12.05 \\
\hline
\end{tabular}

* $\mathrm{pH}$ was measured in suspensions with distilled water at a ratio 1:25 (w/v)

obic biodegradation of compounds. The centrifuge tubes were subsequently capped and shaken in a wrist-action shaker for $6 \mathrm{~h}$ at $20{ }^{\circ} \mathrm{C}$. Preliminary kinetic experiments demonstrate that adsorption equilibrium was reached within 4-6 h and that no detectable amount of the dyes was adsorbed by the polypropylene centrifuge tubes. At the end of the equilibration period the samples were centrifuged at $6000 \mathrm{~g}$ for $15 \mathrm{~min}$ and the supernatant was filtered through fibre-glass filters (Millipore Corp. Bedford, MA, U.S.A.) or by a membrane filter $0.45 \mu \mathrm{m}$ for determination of dye equilibrium concentration.

The column adsorption experiments were carried out in glass columns, $25 \mathrm{~mm}$ i.d. filled with $10 \mathrm{~g} \mathrm{(5 \textrm {cm }}$ height) of fly ash and soil mixtures with the same ratio as in the case of batch experiments (0-20\% in fly ash). The columns were saturated with water and 200-300 $\mathrm{ml}$ of dyes solutions were added at the top of the columns. The concentration of the solutions were 10, 20, 40 and $60 \mathrm{mg} \mathrm{l}^{-1}$ and the flow rate was regulated close to $10 \mathrm{ml} \mathrm{min}^{-1}$.
The effluents were collected every $25 \mathrm{ml}$ and analyzed as described in the previous case of batch experiments.

The concentrations of dyes in the filtrate was determined using a Perkin-Elmer UV-Vis Spectrophotometer, at the dyes absorption maxima (Table 3). The changes of $\mathrm{pH}$ values observed in fly ash and soil aquatic suspensions (Table 1) increase the UV adsorption of dyes solutions. Thus, the calibration curves of dyes at concentrations 1, 5, 10, 20, 40 and $60 \mathrm{mg} \mathrm{l}^{-1}$ were obtained and used in all the $\mathrm{pH}$ values provided by ash and soil mixtures. Triplicate samples were measured for each initial concentration.

\section{RESULTS AND DISCUSSION Adsorption isotherms of batch experiments}

The adsorption isotherms of dyes studied are presented in Figures 2-6. The equilibrium adsorption isotherms are of fundamental importance in the design of adsorption systems. The equilibrium adsorption data could be described satisfactorily

Table 3. The adsorption maxima in $\mathrm{nm}$ of dye solutions in distilled water

\begin{tabular}{lccc}
\hline Dyestuff & Color Index & Abs. maximum (nm) & MW \\
\hline Acid orange 7 (AO-7) & CI 15510 & 490 & 328 \\
Acid yellow 23 (AY-23) & CI 19140 & 420 & 456 \\
Direct yellow 28 (DY-28) & CI 19555 & 390 & 636 \\
Basic yellow 28 (BY-28) & CI 41000 & 428 & 322 \\
Dipserse Blue 79 (DB-79) & CI 11345 & 542 & 625 \\
\hline
\end{tabular}


by the Freundlich isotherm:

$$
\mathrm{x} / \mathrm{m}=\mathrm{K} \cdot \mathrm{C}^{1 / \mathrm{n}}
$$

where $\mathrm{x}$ is the amount adsorbed per mass of adsorbent (m), $\mathrm{C}$ is the equilibrium concentration of dye in solution and $\mathrm{K}$ and $\mathrm{n}$ are Freundlich constants. The constant $\mathrm{K}$, partition coefficient in equilibrium, is positively related to the extent or degree of adsorption, while the constant $\mathrm{n}$ provides a rough estimation of the intensity of adsorption. A linear form of the Freundlich expression will yield the constants $\mathrm{K}$ and $\mathrm{n}$, hence:

$$
\log x / m=\log K+1 / n \log C
$$

The Freundlich equation predicts that the dye concentration on the adsorbent will increase with increase of the dye concentration in the liquid. Table 4 lists the Freundlich constants $\mathrm{K}$ and n, which are calculated from a plot of equation (2). These logarithmic equations for the adsorption of studied dyes on soil-fly ash mixtures gave high lin-

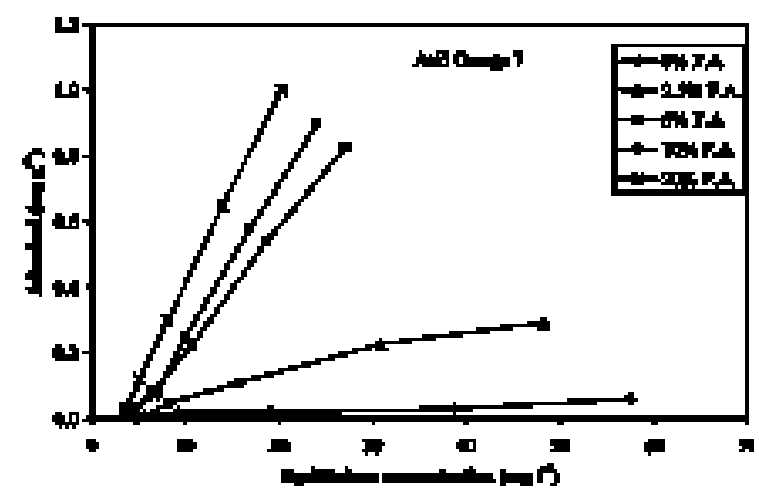

Figure 2. Adsorption isotherms of Acid Orange 7 on suspensions of fly ash and SCL-soil mixtures.

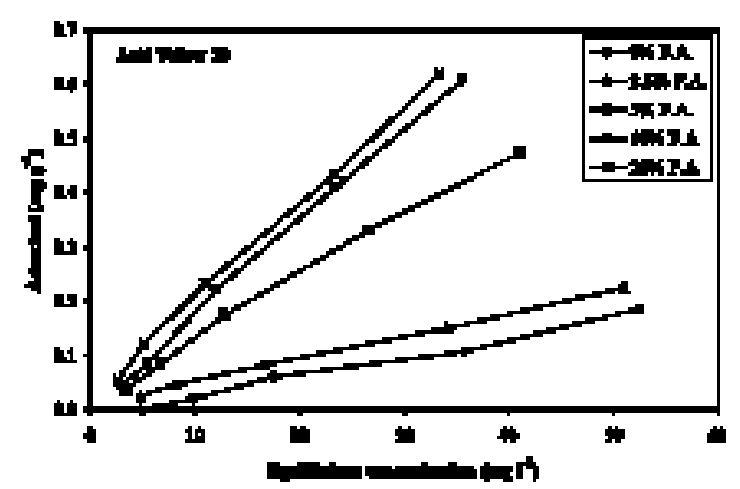

Figure 3. Adsorption isotherms of Acid Yellow 23 on suspensions of fly ash and SCL-soil mixtures. earities, with a range of correlation coefficient between 0.941 and 0.999 . The $\mathrm{K}$ constants increase with the increase of the fly ash content.

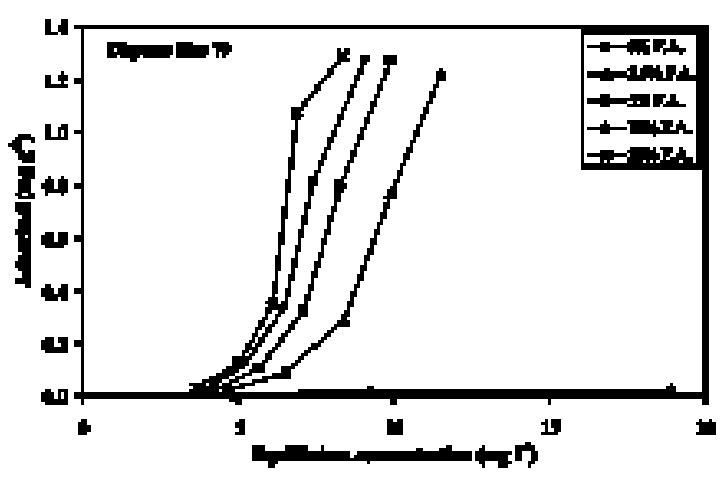

Figure 4. Adsorption isotherms of Disperse Blue 79 on suspensions of fly ash and SCL-soil mixtures.

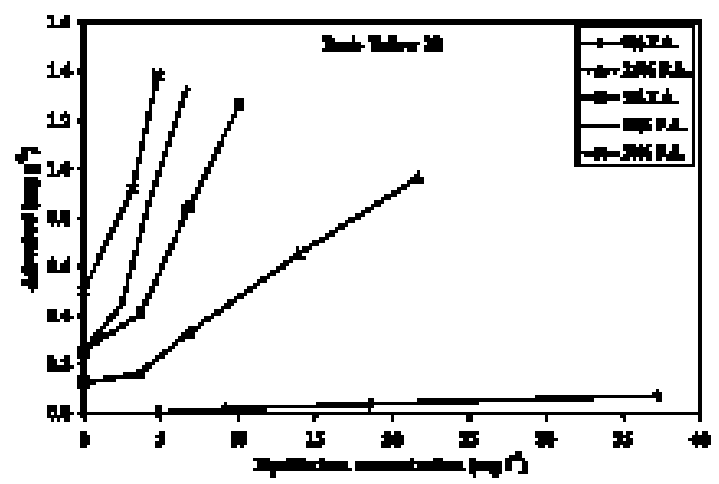

Figure 5. Adsorption isotherms of Basic Yellow 28 on suspensions of fly ash and SCL-soil mixtures.

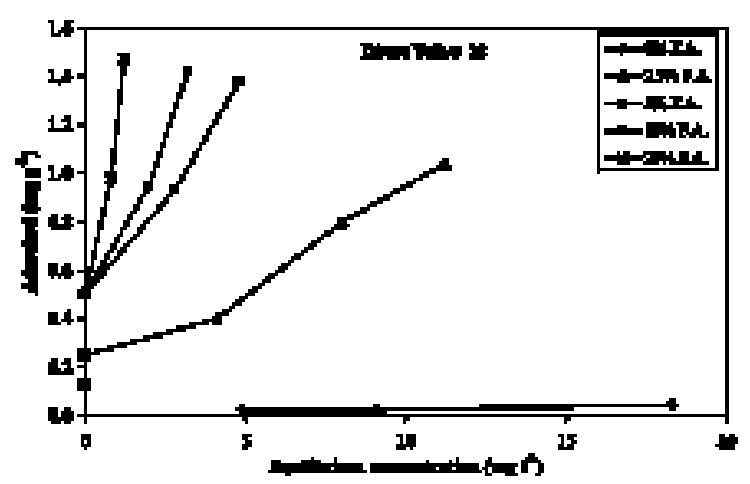

Figure 6. Adsorption isotherms of Direct Yellow 28 on suspensions of fly ash and SCL-soil mixtures. 
Table 4. Freundlich $\mathrm{K}$ and $\mathrm{n}$ constants for the adsorption of dyes in mixtures of fly ash and SCL soil

\begin{tabular}{ccccccccccc}
\hline $\begin{array}{c}\text { Soil } \\
\text { with } \\
\text { fly ash } \\
(\%)\end{array}$ & \multicolumn{2}{c}{ AO-7 } & \multicolumn{2}{c}{ AY-23 } & \multicolumn{2}{c}{ DY-28 } & \multicolumn{2}{c}{ BY-28 } & \multicolumn{2}{c}{ DB79 } \\
\hline 0 & 1.3 & 1.28 & 1.2 & 0.79 & 5.4 & 1.07 & 0.3 & 0.65 & 0.01 & 0.92 \\
$\times 10^{-3}$ & & $\begin{array}{c}\mathrm{K}\left(\mathrm{mg} \mathrm{g}^{-1}\right) \\
\times 10^{-3}\end{array}$ & $\mathrm{n}$ & $\begin{array}{c}\mathrm{K}\left(\mathrm{mg} \mathrm{g}^{-1}\right) \\
\times 10^{-3}\end{array}$ & $\mathrm{n}$ & $\begin{array}{c}\mathrm{K}\left(\mathrm{mg} \mathrm{g}^{-1}\right) \\
\times 10^{-3}\end{array}$ & $\mathrm{n}$ & $\begin{array}{c}\mathrm{K}\left(\mathrm{mg} \mathrm{g}^{-1}\right) \\
\times 10^{-3}\end{array}$ & $\mathrm{n}$ \\
2.5 & 1.7 & 0.71 & 6.2 & 1.09 & 61.6 & 0.96 & 46.6 & 1.00 & 0.02 & 0.22 \\
5 & 1.8 & 0.52 & 11.2 & 0.97 & 436 & 1.06 & 95.5 & 0.89 & 0.02 & 0.20 \\
10 & 2.1 & 0.51 & 14.0 & 0.94 & 526 & 1.17 & 173 & 0.92 & 0.05 & 0.22 \\
20 & 4.0 & 0.52 & 23.9 & 1.07 & 816 & 1.0 & 288 & 1.0 & 0.06 & 0.21 \\
\hline
\end{tabular}

The amount adsorbed from water for a given equilibrium concentration should increase in the order direct yellow $28=$ acid yellow $23>$ basic yellow $28>$ acid orange $7>$ disperse blue 79 .

A strong dependency of $\mathrm{K}$ on the fly ash content (\%F.A.) was found for all sorbent mixtures (Table 5). The relation between the $\mathrm{K}$ constants for each dye and the fly ash content in mixture samples is highly linear and is represented by the following linear equations, with high correlation coefficients (Table 5).

The interstitial free space available for aggregation of adsorbate molecules on the fly ash particle surface is less due to the high temperature at which combustion of lignite occurs and fly ash is formed. Low surface area also shows that fly ash particles do not have many micro or macro pores. For all dyes studies a small decrease in adsorption was observed with increasing dye concentration. The high capacity of fly ash as demonstrated by the present and previous results (Kumar et al., $1987)$ is due to alumina $\left(\mathrm{Al}_{2} \mathrm{O}_{3}\right)$ and silica $\left(\mathrm{SiO}_{2}\right)$ and calcium oxide $(\mathrm{CaO})$, which adsorb the ionic forms of dyes as well as to the organic carbon content which adsorbs mainly the molecular forms of dyes.

\section{Batch removal of dyes by adsorption from aquatic solutions}

The removed amounts of dyes by adsorption on fly ash mixtures with soil are summarized in Table 6 . The amounts which are illustrated in Figure 7 are in regard to the adsorbed amounts and are correlated with the fly ash content.

As we have already concluded from the Freundlich constants adsorption increases with fly ash content and the dye solubility (hydrophilic character) decrease.

\section{Removal of dyes by adsorption on columns}

The removal of dyes by adsorption on column composed of fly ash and soil mixtures reach equilibrium conditions when the adsorbent mixture stops adsorbing the solute dye. The adsorption equilibrium point is indicated by the concentration of dyes in the effluent. At this point the concentration of the dye in the effluent becomes equal to the initial concentration. The ratio between adsorbent mixtures and dyes solutions was 1:20 (w/v) except for the disperse blue 79 where the ratio was $1: 30(\mathrm{w} / \mathrm{v})$ in the column experiments in order to reach the equilibrium conditions. Although these ratios are close to that

Table 5. Correlations between the partition coefficient $\mathrm{K}$ of dyes and fly ash content (\%) in mixtures with soil

\begin{tabular}{lccc}
\hline Compounds & \multicolumn{3}{c}{ Correlations } \\
& $\mathrm{a}=\mathrm{K}[\%$ F.A.]+b & $\mathrm{R}^{2}(\mathrm{n}=3)$ \\
\hline Acid Orange 7 & $0.14 \times 10^{-3}$ & $\mathrm{~b}$ & 0.967 \\
Acid Yellow 23 & $1.06 \times 10^{-3}$ & $3.1 \times 10^{-3}$ & 0.980 \\
Direct Yellow 28 & 0.04 & 0.067 & 0.944 \\
Basic yellow 28 & $14.2 \times 10^{-3}$ & $13.8 \times 10^{-3}$ & 0.993 \\
Disperse Blue 79 & $2.5 \times 10^{-6}$ & $13.1 \times 10^{-6}$ & 0.948 \\
\hline
\end{tabular}

where [\%F.A.] = Percentage of fly ash content in mixtures with soil 
Table 6. Adsorbed (removed) amount $\%$ of dyes on mixtures of fly ash and soil from aqueous solutions with a range of concentrations $5-60 \mathrm{mg} \mathrm{l}^{-1}$.

\begin{tabular}{clrrrrr}
\hline Dye & & \multicolumn{5}{c}{ Fly ash content (\%) } \\
& & 0 & 2.5 & 5 & \multicolumn{1}{c}{10} & \multicolumn{1}{c}{20} \\
\hline Acid Orange 7 & Mean (\%) & 4.9 & 14.1 & 41.1 & 43.9 & 53.0 \\
& Range (\%) & $3.1-6.0$ & $7.2-23.7$ & $16-55$ & $22-60$ & $24.8-66.8$ \\
Acid Yellow 23 & Mean (\%) & 7.2 & 13.2 & 39.9 & 40.8 & 44.9 \\
& Range (\%) & $6-12.5$ & $2-16.4$ & $30-68.7$ & $38-40.9$ & $41.2-48$ \\
Direct Yellow 28 & Mean (\%) & 6.9 & 88.8 & 96.9 & 97.8 & 99.2 \\
& Range (\%) & $2-9$ & $79.5-100$ & $92-100$ & $94.6-100$ & $98-100$ \\
Basic Yellow 28 & Mean (\%) & 6.1 & 71.8 & 82.4 & 83.2 & 96.8 \\
& Range (\%) & $2-9$ & $63-100$ & $65-100$ & $89-100$ & $92-100$ \\
Disperse Blue 79 & Mean (\%) & 5.9 & 51.6 & 57.7 & 60.7 & 88.5 \\
& Range (\%) & $4-8$ & $8-80.8$ & $16-83.4$ & $22-84.8$ & $26-86$ \\
\hline
\end{tabular}

of batch experiments $(1: 25 \mathrm{w} / \mathrm{v})$ the estimated values of the partition coefficient $\mathrm{K}$, which show the adsorbed mass of dye per mass unit of adsorbent (g) at equilibrium concentration of dye $1 \mathrm{mg} \mathrm{l}^{-1}$, are about 1000 to 10,000 times lower than the values of Freundlich constant K calculated for the same compounds in batch experiments. This large difference shows that in column adsorption experiments only a small part of the adsorbent surface is available for the adsorption process. The low adsorptive capacity is also attributed to the short equilibrium time, 20-30 min, in column experiments which is $12-18$ times shorter than that of batch experiments.

The removal of dyes decreases with the increase in solution concentration from 10 to $60 \mathrm{mg} \mathrm{l}^{-1}$ at

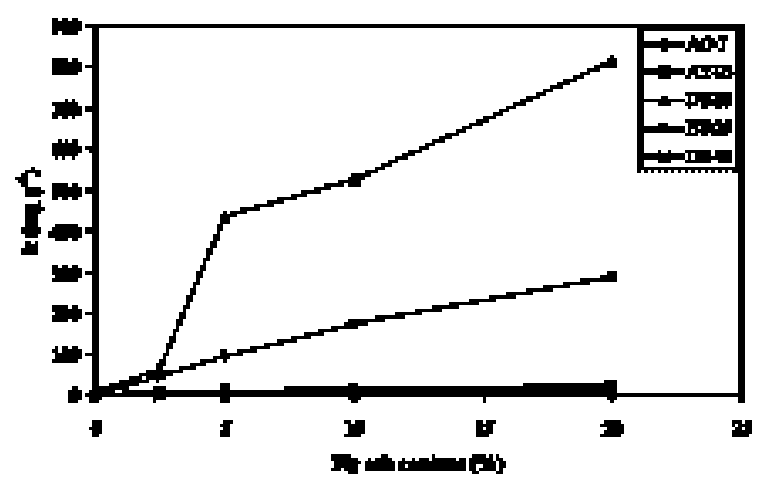

Figure 7. The relation between the adsorption constant $\mathrm{k}$ and the soil fly ash content for the dyes used.

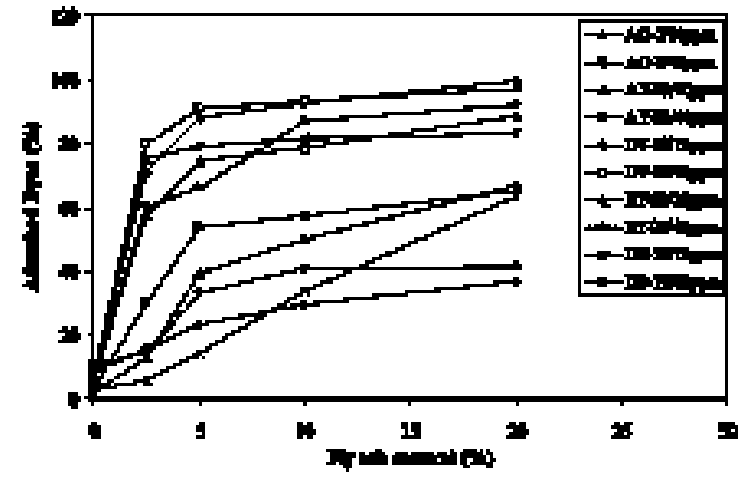

Figure 8. Percent amounts of dyes adsorbed in columns of fly ash and soil mixtures from aqueous solutions at concentrations of 10 and $40 \mathrm{mg} \mathrm{l}^{-1}$.

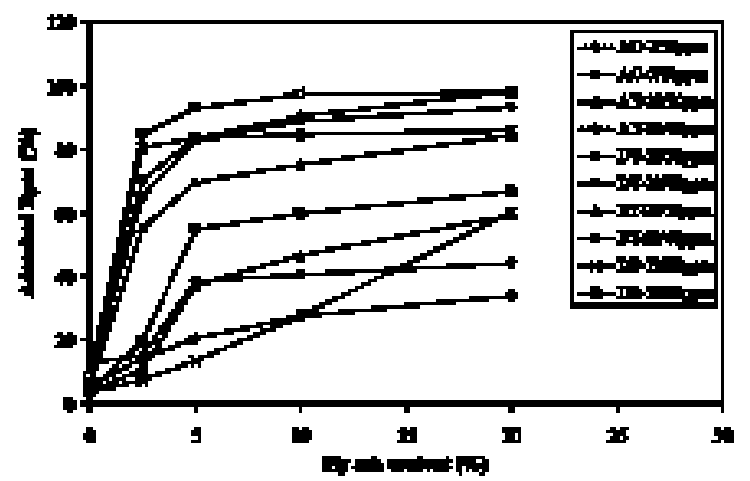

Figure 9. Percent amounts of dyes adsorbed in columns of fly ash and soil mixtures from aqueous solutions at concentrations of 50 and $60 \mathrm{mg} \mathrm{l}^{-1}$. 
$20{ }^{\circ} \mathrm{C}$, showing the process to be highly dependent on the concentration of the solution (Figures $8,9)$. The mean removed amounts of dyes by adsorption on columns of soil mixture with $20 \%$ fly ash content and for initial concentration of dye solutions $50 \mathrm{mg} \mathrm{l}^{-1}$ are up to $33.8 \%$ for acid orange $7,59.4 \%$ for acid yellow $23,84.2 \%$ for direct yellow $28,98.2 \%$ for basic yellow 28 and $60.3 \%$ for disperse blue 79 .

Results of leaching tests of metals from mixtures of fly ash and soil in batch experiments have shown that fly ash could be used also for other organic pollutants such as chlorophenols removal from aqueous solutions, more safely, after prewashing of the easily released $\mathrm{Cr}$ and $\mathrm{Cu}$ in alkaline conditions (Danis and Albanis, 1996). The development of fly ash prewashing methods will be the next step of this research.

\section{CONCLUSIONS}

From the presented study, it may be concluded that the removal of dyes from aqueous solutions by adsorption on fly ash and soil mixtures has been found to be useful means for controlling the water pollution due to dyes. The important characteristics and results of the methodology, are:

1. The results of the present batch studies show that the adsorption of azo-dyes (acid, basic, direct and in dispersed solid form) on soil-fly ash mixtures is quite satisfactory.

2. The linear isotherms indicate a constant partition of dyes between the bulk solution and soil-fly ash mixtures, for a concentration range from 5 to $60 \mathrm{mg} \mathrm{l}^{-1}$. The high correlation coefficient $\left(\mathrm{R}^{2}\right)$ indicates that the high affinity between fly ash surface and basic, direct and disperse dyes plays the major role in the adsorption mechanism.

3. Mass balance estimations show that the removed amounts of dyes by adsorption in fly ash mixtures with soil sample containing $20 \%$ fly ash are up to $53.0 \%$ for acid orange 7 , $44.9 \%$ for acid yellow $23,99.2 \%$ for direct yellow $28,96.8 \%$ for basic yellow 28 and $88.5 \%$ for disperse blue 79 .

4. The removal of dyes from column experiments decreases with the increase of the solution concentration from 10 to $60 \mathrm{mg} \mathrm{l}^{-1}$ at $20{ }^{\circ} \mathrm{C}$, showing the process to be highly dependent on the concentration of the solution.

5. The mean removed amounts of dyes by adsorption on columns of soil mixture with $20 \%$ fly ash content and for initial concentration of dye solutions $50 \mathrm{mg} \mathrm{l}^{-1}$ are up to $33.8 \%$ for acid yellow 7, 59.4\% for acid yellow 23, $84.2 \%$ for direct yellow $28,98.2 \%$ for basic yellow 28 and $60.3 \%$ for disperse blue 79 .

The major advantages of an adsorption system for water pollution control are less investment in terms of both initial cost and land, simple design and easy operation, no effect by toxic substances, and superior removal of organic waste constituents as compared to the conventional biological treatment processes (Gupta et al., 1988). The adsorption techniques have been found to be useful means for controlling the extent of water pollution due to dyes. Fly ash is a material showing the pronounced removal of azo dyes from aqueous solutions in alkaline conditions.

\section{REFERENCES}

Albanis, T.A., Danis, T.G and Kourgia, M. (1998), Adsorption-desorption studies of selected chlorphenols and herbicides and metal release in soil mixtures with fly ash and soil, Environmental Technology, 19, 25-34.

Anliker, R., Clarke, E.A. and Moser, P. (1981), Use of the partition coefficient as an indicator of bioaccumulation tendency of dyestuffs in fish, Chemosphere, 10, 263-274.

Arvanitoyannis, I., Eleftheriadis, I. and Kavlentis, E. (1987), Treatment of dye containing effluents with different bentonites, Chemosphere, 16, 2523-2529.

Arvanitoyannis, I., Eleftheriadis, I. and Tsatsaroni, E. (1989), Influence of pH on adsorption of dye-containing effluents with different bentonites, Chemosphere, 18, 1707-1711.

Baughman, G. and Perenich, T.A. (1988), Fate of dyes in aqueous systems: Solubility and partitioning of some hydrophobic dyes and related compounds, Environ. Toxicol. Chem., 7, 183-199.

Clarke, E.A. and Anliker, R. (1980), Organic dyes and pigments. In: The Handbook of Environmental ChemistryVol. 3. Part A. Anthropogenic Compounds, Hutzinger, O. (Ed.), Springer-Verlag, Heidelberg, 181-215.

Davis, L. and Randal, C. (1978), Development of color removal potential in organisms treating pulp and paper wastewaters, J. WPCF, 50, 382-386. 
Gupta, G.S., Prasad, G., Panday, K.K. and Singh, V.N. (1988), Removal of chrome dye from aqueous solutions by fly ash, Water Air and Soil Pollution, 37, 13-24.

Kumar, S., Upadhyay, S.N. and Upadhya, Y.D. (1987), Removal of phenols by adsorption on fly ash, J. Chem. Tech. Biotechnol, 37, 281-290.

Laing, I.G. (1991), The impact of effluent regulations on the dyeing industry, Rev. Prog. Coloration, 21, 56-71.

Mavros, P., Daniilidou, A.C., Lazaridis, N.K. and Stergiou, L. (1994), Color removal from aqueous solutions. Part I, Flotation. Environ. Technol, 15, 601-616.

Mortland, M.M., Shaobai, S. and Boyd, S.A. (1986), Clay-organic complexes as adsorbents for phenol and chlorophenols, Clays \& Clay Minerals, 34, 581-585.

Nyholm, N., Jacobsen, B.N., Pedersen, B.M., Poulsen, O., Damborg, A. and Schultz, B. (1992), Removal of organic micropollutants at ppb levels in laboratory activated sludge under various operating conditions, Water Resources, 26, 339-353.

Pagga, U.M. and Taeger, K. (1994), Development of a method for adsorption of dyestuffs on activated sludge, Water Resources, 28, 1051-1057.

Pollock, M. (1973), Neutralizing dye-house wastes with flue gases and decolorizing with fly ash, American Dyestuff Reporter, 62, 21-23.

Sturm, K., Williams, E. and Macek, K.J. (1975), Fluorescent whitening agents. Acute fish toxicity sand accumulation studies, Water Resources, 9, 211-219. 